\title{
Early Laparoscopic Cholecystectomy for Acute Cholecystitis in a Cohort of Sudanese Patients: Outcome and Complications in Minimum Resource- Settings
}

\author{
Elamin Yassin Elsamani ${ }^{*}$, Walid Elhaj Abd Elrahim ${ }^{2}$, Eltahir Awad Gasim Khalil ${ }^{3}$, Eltaib A Saad ${ }^{2}$, AM \\ Awadelkarim² and Kamal E Elzaki Elsiddig² \\ ${ }^{1}$ Sudan Medical Specialization Board, Khartoum, Africa \\ ${ }^{2}$ Department of General Surgery, University of Khartoum, Africa \\ ${ }^{3}$ Department of Clinical Pathology \& Immunology, University of Khartoum, Africa
}

Submission: October 09, 2017; Published: October 26, 2017

*Corresponding author: ElaminYassin Elsamani, Sudan Medical Specialization Board, Khartoum, Sudan P.O. Box 102, Post code 11111, Tel: 249961164324; Email: eltahirk@iend.org

\begin{abstract}
Background: Early laparoscopic cholecystectomy (ELC) is advocated as an emergency procedure to manage acute cholecystitis. It is safe, with early return to daily activities, less post-operative pain and better cosmoses. This study evaluated the safety of ELC in the management of acute cholecystitis in a cohort of Sudanese patients.

Patients and methods: This was a descriptive, retro-prospective, analytical and hospital-based multi-centre study. Following informed consent, seventy patients with acute cholecystitis who fulfilled the inclusion/exclusion criteria were studied. Patients with acute pancreatitis, severe sepsis and gallbladder stones were excluded.
\end{abstract}

Results: Patients had a mean age of $47.7 \pm 13.7$ years and a male: female ratio of 1:5. More than half of the patients $(57.1 \%, 40 / 70)$ had symptoms for less than 72 hours. More than half $(58 \%, 41 / 70)$ had surgery within three days of the onset of symptoms, 28.6\% (20/71) underwent the operation within 4-7days. Conversion rate into open surgery was reported in $10 \%(7 / 70)$. The mean time for surgery was $90.7 \pm 32$ minutes. Post-operative complications were encountered in 10\% (7/70) of patients. The average duration of hospital stay was $43.8 \pm 42$ hours.

Conclusion: Early Laparoscopic cholecystectomy is reliable and safe for the management of acute cholecystitis. It can be performed within any time following symptoms onset.

Keywords: Cholecystitis; Early laparoscopic cholecystectomy; Conversion; Sudan

\section{Introduction}

Acute cholecystitis is an inflammatory process presenting with biliary colic that is unremitting and may persist for several days. Obstruction of the cystic duct by a gallstone is the initiating event that leads to distention, inflammation and edema of the gallbladder wall. When the gallbladder remains obstructed and secondary bacterial infection supervenes, an acute gangrenous cholecystitis develops and an abscess or empyema forms within the gallbladder. The perforation usually is contained in the sub-hepatic space by the omentum. Early cholecystectomy performed within 2-3 days of the illness is preferred over interval or delayed cholecystectomy that is performed 6-10 weeks after initial medical treatment and recuperation. Early laparoscopic cholecystectomy (ELC) has been advocated as an emergency procedure to manage acute cholecystitis. Provided that the operation is undertaken within 2-3 days of the onset of the attack, with an experienced surgeon and excellent operating facilities are available, good results can be achieved. The obvious advantages of ELC to the patients include: decrease burden, early return to daily activities, less post-operative pain and better cosmoses [1-3]. This study aimed to evaluate the safety of ELC in the management of acute cholecystitis in a cohort of Sudanese patients in minimum resources settings.

\section{Patients and Methods}

This is a multicentre study that was conducted in minimal access Surgery Departments in Atbara Medical Complex, Atbara, 
River Nile State and Fedail Specialized Hospital, Khartoum during the period from February 2012 to July 2016. All patients had cholecystitis diagnosed clinically and by imaging. Patients who were diagnosed as acute cholecystitis and who underwent early laparoscopic cholecystectomy during the study period were included. Patients with acute pancreatitis, severe sepsis and common bile duct stones were excluded. Timing of surgery from onset of symptoms, conversion rate and operative complications were recorded.

\section{Results}

\section{Patients' demography}

seventy patients with acute and acute-on-chronic cholecystitis were studied. Male: Female ratio of 1: 5 [10/70, $14.3 \%$ were males and $85.7 \% 60 / 70]$, with a mean age of $47.7 \pm 13.7$ years [range 19-86 years]. The majority of patients $(64.3 \%, 45 / 70)$ had BMI of $25-30$. The majority $(78 \%, 55 / 70)$ had no previous surgical scars, among those who had previous scars, Pfennestiel scar was the most common. Five patients were pregnant, four of them were in the first trimester and one was in her second trimester.

\section{Duration of symptoms}

The mean duration of symptoms to the time of surgery was $5.6 \pm 6.1$ days. Fifty per cent $(35 / 70)$ of patients had symptoms duration of $1-3$ days, while $28.6 \%$ (20/70) had duration between 4-7days. The rest (21.4\%) had duration of more than seven days.

\section{Timing of surgery}

Fifty eight per cent $(41 / 70)$ had surgery within the first attack of acute cholecystitis, and $28 \%$ underwent the operation with previous history of similar attack. Fifty per cent (35/70) of patient were operated on in the first 3 days of onset symptoms. Twenty patients $(28.6 \%, 20 / 70)$ had surgery after 4-7 days, while $15 / 70$ (21.4\%) patients had surgery after 7 days. The cystic duct was secured by clippings in three quarters of patients $(75.5 \%, 53)$, whereas intra-corporal knotting was applied in about a quarter $(24 \%, 17 / 70)$.

\section{Subtotal Surgery}

Table 1: Association between duration of symptoms, hospital stay and duration of surgery.

\begin{tabular}{|c|c|c|c|c|}
\hline & \multicolumn{3}{|c|}{ Duration of Symptoms } & \multirow{2}{*}{ p value } \\
\hline & 1-3 days & 4-7 days & $>7$ days & \\
\hline \multicolumn{4}{|c|}{ Hospital stay } & 0.34 \\
\hline 24 & 21 & 11 & 5 & \\
\hline $24-72$ & 14 & 9 & 9 & \\
\hline$>72$ & 0 & 0 & 1 & \\
\hline \multicolumn{4}{|c|}{ Duration of surgery } & 0.897 \\
\hline$<60 \mathrm{~min}$ & 10 & 4 & 3 & \\
\hline $60-120 \mathrm{~min}$ & 21 & 14 & 10 & \\
\hline$>120 \min$ & 2 & 2 & 2 & \\
\hline
\end{tabular}

Partial cholecystectomy was performed in ten $(10 / 70$, $14.3 \%)$ patients. Drain insertion was performed in seven $(7 / 70$, $10 \%)$ patients. The mean time for surgery was $90.7 \pm 32$ minutes (1.5 hour) with [range 30-240 minutes]. More than two thirds of the patients $(72 \%, 50 / 70)$ had operation duration of 60 to 120 minutes. The duration of symptoms since onset until time of surgery was not significantly associated with period of hospital stay and duration of surgery in minutes ( $p$ value $0.34,0.897$ ) respectively (Table 1 ). The duration of symptoms since onset was not significantly associated with performing subtotal surgery ( $p$ value 0.112 ); moreover there were significant associations between duration of symptoms and occurrence of bile leak as post-operative complication ( $p$ value 0.023 ). Nevertheless, the association between duration of symptoms and occurrence port site infection, port site hernia as postoperative specific complication were not significantly associated ( $\mathrm{p}$ value 0.680 , 0.647 respectively) (Table 2).

Table 2: Association between duration of symptoms, subtotal surgery and postoperative complications.

\begin{tabular}{|c|c|c|c|c|c|c|c|}
\hline & \multicolumn{6}{|c|}{ Duration of symptoms } & \multirow{3}{*}{$P$ value } \\
\hline & \multicolumn{2}{|c|}{ 1-3 days } & \multicolumn{2}{|c|}{ 4-7days } & \multicolumn{2}{|c|}{$>7$ days } & \\
\hline & yes & no & yes & no & Yes & No & \\
\hline Bile leak & 0 & 35 & 0 & 20 & 2 & 13 & 0.023 \\
\hline Port site infection & 1 & 34 & 1 & 19 & 0 & 15 & 0.680 \\
\hline Port site Hernia & 2 & 33 & 1 & 19 & 0 & 15 & 0.647 \\
\hline Subtotal cholecystectomy & 2 & 33 & 5 & 15 & 3 & 12 & 0.112 \\
\hline
\end{tabular}




\section{Conversion to open surgery}

Conversion to open surgery was reported in 10\% (7/70) of patients for different indications e.g. obscure anatomy at Calot's triangle [commonest cause].

\section{Post-operative complications}

post-operative complications were reported in $10 \%(7 / 70)$ of patients. The most commonly observed complication was Port-site hernia $(4.3 \%, 3 / 70)$, followed by Port-site infection and biliary leak $(2.9 \%, 2 / 70$ each). However; no cases of post-operative bleeding or retained stones were reported. No mortality was reported during hospital stay or during three-months of follow-up. Two patients had biliary leak and underwent exploratory laparotomy. The first patient had a clipped cut through cystic duct and developed biliary peritonitis and was explored on the second day postoperatively and the cystic duct was re-secured using Proline 6/0. She stayed in the hospital for 15 days and was discharged in good health. The second patient was readmitted one week after discharge with signs of sepsis, the ultrasound showed a free fluid collection in peri-hepatic space. An exploration was done and the cystic duct was found to be cut through by the clips, a repair was done using the same method described in the first case. An intra-operative US was used to confirm the integrity of extra hepatic biliary system, the patient recovered and was discharged in good health.

The mean duration of hospital stay was $43.8 \pm 42$ hours, with more than half of the patients $(52.9 \%, 37 / 70)$ staying for 24 hours. The age was not significantly associated with the operation duration, postoperative specific complications, conversion rate or hospital stay ( $\mathrm{p}$ values were $0.2,0.9,0.6$ and 0.5 respectively). Similarly, gender was not significantly associated with any of the above variables. Existence of co-morbidities did not affect the rate of complications, conversion or duration of both operation time and hospital stay duration. Presence of previous surgical scar was not significantly associated with conversion rate, occurrence of complications, operative time or hospital stay ( $\mathrm{p}$ value were $0.96,0.96,0.97$ and 0.49 respectively). The association between conversion and age, sex, BMI, Gallbladder wall thickness and duration of symptoms are summarized in (Table 3). There were no significant associations ( $p$ value were $>0.05$ ) except the with Gallbladder wall thickness ( $p$ value were 0.007).

Intra-operative status of the gallbladder was significantly associated with methods of securing the cystic duct and operation status $(\mathrm{P}<0.001)$. Clips were used in the majority of cases of acute oedematous gallbladder (86.6\%), whereas knotting was applied in the presence of severe inflammation (55\%). It was also significantly associated with performance of subtotal surgery ( $\mathrm{p}=0.001), 70 \%$ of subtotal surgery was required in cases of severely inflamed gallbladder. In addition; $85 \%$ of conversion cases were associated with severely inflamed gallbladders $(\mathrm{p}<0.001)$. Moreover; the majority $(71.4 \%)$ of postoperative complications occurred in those with severely inflamed gallbladder $(\mathrm{P}=0.004)$.

Furthermore; the vast majority (85\%) of drains were inserted in operations for severely inflamed gallbladder $(\mathrm{P}=0.001)$. The duration of hospital stay was also significantly associated with operation status of the gallbladder $(\mathrm{P}<0.001)$. However, it was observed that the presence of oedematous gallbladder was reported in the great majority $(82 \%, 57 / 70)$ of cases that were operated on during the first 72 hours. Oedematous gallbladder was seen in two thirds (65\%) of those who had surgery between 4-7 days and in 55\% of those who underwent surgery after 7 days. No significant association between occurrence of specific complications and gender, BMI or GB wall thickness were reported $(\mathrm{P}>0.05)$.

\section{Discussion}

Laparoscopic cholecystectomy (ELC) is the procedure of choice for acute cholecystitis (AC). Early cholecystectomy offers patients with acute cholecystitis a definitive solution in one hospital admission with swift recovery time and an earlier return to work. The mean age of presentation and female predominance in our cohort is similar to previous reports [3-8]. Our results showed that ELC can be performed for AC within any time regardless the time of symptoms onset of acute cholecystitis. The term "early" is quite confusing in the literature as some studies refer to it as the duration between onset of the symptoms and time of surgery [9-11]. Other reports consider it as the time lag between hospital admission and the time of surgery $[12,13]$. In overall; it can be concluded that for "early" laparoscopic cholecystectomy and acute cholecystitis, the "standard" timing of "early" surgery is not well established [14]. However; most studies have reported an optimal delay to surgery of up to 72 hours [15].

Our study results showed there is no significant different regarding the timing of surgery. ELC can be performed for AC within any time regardless of the time of symptoms onset of acute cholecystitis. Intra-operative status of the gallbladder was also significantly associated with increased rates of subtotal cholecystectomy $(\mathrm{P}=0.001)$, where $70 \%$ of subtotal surgeries were required in cases of severely inflamed gallbladder. This is concordant to previous reported on the safety of subtotal cholecystectomy in cases of severely inflamed gall bladder $[10,14,16]$. Moreover; post-operative complications in patients with severely inflamed gallbladder were concordance with previous studies $[10,11,17]$.

Laparoscopic cholecystectomy conversion in our series is within the range [range 5-31\%] reported in earlier studies. The variability in the conversion rate is attributed to differences in patient demographics, severity of inflammation, surgeon's experience and timing of early laparoscopic cholecystectomy [14-19]. The commonest indications of conversion in our study included obscured/ difficult anatomy, failure of progression and 
intra-hepatic gall bladder and were similar to a study by Peng et al. [9]. On the other hand Hadad et al. [15] and Qureshi et al. [17] reported that the common cause of conversion is presence of adhesion [20].

Gender did not affect the rate of conversion, a finding discordant with previous reports [6]. Gender was found to be an independent risk factor for conversion during early laparoscopic cholecystectomy similar to previous reports. A higher conversion rate reported in males may be explainable by possible delay in the seeking of medical advice or difference in the disease pattern as has been suggested previously $[6,14]$. The prevalence of postoperative complications was not different from previous reports. Mortality was not reported during hospital stay or at 3 month of follow-up and this is comparable to what reported previously. The mean time to surgery was comparable to previous reports, while other reports showed that the most significant disadvantage of laparoscopic cholecystectomy (LC) was the relatively longer duration of surgery. The average duration of hospital stay in our cohort was comparable to previous reports and was significantly associated with complications and conversion [21-23].

\section{Conclusion}

In conclusion, early laparoscopic cholecystectomy (ELC) for the management of acute cholecystitis is safe with few complications in minimal access settings. ELC can be performed within any time regardless the time of symptoms onset.

\section{References}

1. Eldar S, Sabo E, Nash E, Abrahamson J, Matter I (1997) Laparoscopic cholecystectomy for acute cholecystitis: prospective trial. World J Surg 21(5): $540-545$

2. Kevin C, Williams NS, Bulstrode CJK, Oconnell PR Baily (2008) The gall bladder and bile ducts. Love's Short Practice of Surgery, $25^{\text {th }}$ edn Arnold International Students Edition, London, UK, pp. 1119-1122.

3. Musa AM, Adam MA, Hamza AA (2006) Audit of laparoscopic cholecystectomy Omdurman Teaching Hospital. Sudan Med J 3(1): 1-9.

4. Zehetner J, Degnera E, Olasky J, Mason RA, Drangsholt S, et al. (2014) Percutaneous cholecystostomy versus laparoscopic cholecystectomy in patients with acute cholecystitis and failed conservative management a matched-pair analysis. Surg Laparo Endo Per 24(6): 523-607.

5. Fuks D, Duhaut P, Mauvais F, Pocard M, Haccart V, et al. (2015) A retrospective comparison of older and younger adults undergoing early laparoscopic cholecystectomy for mild to moderate calculous cholecystitis. J Am Geriatr Soc 63 (5): 1010-1016.

6. Ambe PC, Kohler L (2015) Is the male gender an independent risk factor for complication in patients undergoing laparoscopic cholecystectomy for acute cholecystitis? Int Surg J 100(5): 854-859.

7. Ambe P, Weber SA, Christ H, Wassenberg D (2014) Cholecystectomy for acute cholecystitis. How time-critical are the so called "golden 72 hours"? Or better "golden 24 hours" and "silver 25-72 hour"? A case control study. World J Emerg Surg 9(1):60.
8. Gutt CN, Encke J, Koninger J, Harnoss JC, Weigand K, et al. (2013) Acute cholecystitis: early versus delayed cholecystectomy, a multicenter randomized trial (ACDC study, NCT00447304). Ann Surg 258(3): 385393.

9. Peng WK, Sheikh Z, Nixon SJ, Paterson Brown S (2005) Role of laparoscopic cholecystectomy in the early management of acute gallbladder disease. Br J Surg 92(5): 586-591.

10.Saber A, Hokkam EN (2014) Operative outcome and patient satisfaction in early and delayed laparoscopic cholecystectomy for acute cholecystitis. Minn Surg 2014: 4.

11. Ciftci F, Abdurrahman I, Girgin S (2015) The outcome of early laparoscopic surgery to treat acute cholecystitis: a single-center experience. Int J Clin Exp Med 8(3): 4563-4868.

12. Liguori G, Bortul M, Castiglia D (2002) The treatment of laparoscopic cholecystectomy for acute cholecystitis. Ann Ital Chir 74(5): 517-521.

13. Kolla SB, Aggarwal S, Kumar A, Parshad R, Seenu V (2004) Early versus delayed laparoscopic cholecystectomy for acute cholecystitis: a prospective randomized trial. Surg Endosc 18(9): 1323-1327.

14. Gharaibeh KI, Qasaimeh GR, Al-Heiss H, Ammari F, Bani Hani K, et al. (2002) Effect of timing of surgery, type of inflammation, and sex on outcome of laparoscopic cholecystectomy for acute cholecystitis. J Laparoendosc Adv Surg 12(3): 193-198.

15. Hadad SM, Vaidya JS, Baker L, Koh HC, Heron TP, et al. (2007) Delay from symptom onset increases the conversion rate in laparoscopic cholecystectomy for acute cholecystitis. World J Surg 31(6): 13001303.

16. Soleimani M, Mehrabi A, Buchler MW, Schmidt J (2007) Partial cholecystectomy as a safe and viable option in the emergency treatment of complex acute cholecystitis: a case series and review of the literature. Am Surg 73(5):498-507.

17. Qureshi A, Haider J, Aziz A (2012) Early Laparoscopic Cholecystectomy for Acute Calculous Cholecystitis: literature. Am Surg 73(5): 498-507.

18. Cox MR, Wilson TG, Luck AJ, Jeans PL, Padbury RT, et al. (1993) Laparoscopic cholecystectomy for acute inflammation of the gallbladder. Ann Surg 218(5): 630-634.

19. Chahin F, Elias N, Paramesh A, Saba A, Godziachvili V, et al. (1999) The efficacy of laparoscopy in acute cholecystitis. J Soc Laparoendosc Surg 3(2): 121-125.

20. Kum CK, Eypasch E, Lefering R (1996) Laparoscopic cholecystectomy for acute cholecystitis: is it really safe?. World J Surg 20(1): 43-49.

21. Colonval P, Navez B, Cambier E (1996) Is laparoscopic cholecystectomy effective and reliable in acute cholecystitis? Results of a prospective study of 221 pathologically documented cases. Ann chir 51(7): 689696.

22. Zhu B, Zhang Z, Wang Y, Gong K, Lu Y, et al. (2012) Comparison of laparoscopic cholecystectomy for acute cholecystitis within and beyond $72 \mathrm{~h}$ of symptom onset during emergency admissions. World J Surg 36(11): 2654-2658.

23. Carbajo CM, Martin DO, Vaquero PC (1998) Surgical treatment of the acute cholecystitis in the laparoscopic age. A comparative study: laparoscopy against laparatomy. Rev Esp Enferm Dig 90(11): 788-793. 
This work is licensed under Creative Commons Attribution 4.0 Licens

DOI: 10.19080/OAJS.2017.06.555694 